\title{
PARAMETER CHARACTERIZATION IN PROCESSING OF SILVER - ALUMINUM BASED ELECTRICAL CONTACT MATERIALS
}

\begin{abstract}
An electrical contractor is one which plays significant role in day todays life in industries as well as in home appliances. In current scenario the materials for conducting purpose has an overwhelming research capability. Now a day the silver based electrical contact composite material have provided the potential applications in aerospace and automobile industries. Among silver based contact material the silver cadmium oxide and silver tin oxide plays a vital role in fabrication of electrical contactors. In this research an attempt has been made to study the influence of adding Aluminum with silver based electrical contact composite materials by two different processing routes namely stir-casting and powder metallurgy. Silver and aluminum matrix plays a virtual role in composite world owing to their highest conductivity. Optimum parameters were identified for attaining the maximum properties such as conductivity, hardness, density, and porosity of composition. By this better conducting property and mechanical property of the electrical contact can be improved by this system. Thus a screening test has be conducted with addition of Al with silver tin oxide compositions hence this paper aims to process the aluminum - silver based electrical contact materials by stir casting processing and powder metallurgy route and compare the results obtained.
\end{abstract}

Keywords: Electrical contactor, Silver, Aluminum, Tin oxide, and conduction

\section{Introduction}

In our everyday life the utilization of electrical switch is generally expanding. The unwavering quality of electrical hardware rely upon the nature of gadgets, for example, switches, electrical switch or hand-off that interface, hinder and separate the electrical current. The electrical switch comprise of electrical contact loops, spring, outline, turn and so on. In the switches, the electrical contractor assumes a principal part in reaching electrical current. The contactor have their application in controlling the electrical engines, lighting, warmer, capacitor banks, warm evaporators and other electrical burdens Electromechanical contactors are used in applications that require circuit making and breaking, for example, electrical automatisms, railroads, electric vehicles, circuits containing starter engines, radiators, and lighting applications. In these days many of them are being used and they can't be supplanting within a reasonable timeframe by electronic switches. There are numerous purposes behind this, for example, their extensive over-burden limit, vast separation capacity of the exchanging hole and heartlessness to voltage spikes which can prompt the annihilation of the electronic switches. Not at all like electronic switches, electromechanical contactors have the weakness of the mechanical removal of some of their parts and the wear related with that. This mechanical development causes the contacts to affect amid conclusion. The shutting speed and the speed of the versatile center amid effect have an incredible significance on the conduct of the gadget [1]. This effect amid conclusion is the starting point of the contact skip, otherwise called babble. It is an undesirable marvel, which brings about a re-opening of the contacts, creating the ghost of an electric circular segment until the contact makes unquestionably [2]. The curve can bring about extreme contact disintegration, and consequently the electrical life and unwavering quality of the contacts are drastically decreased [3,4]. An ascent in the contact temperature causes a more noteworthy increment in the contact resistance. This procedure might debase the contact [5]. The paper concentrates on novel methodology of addition of Aluminium (Al) with silver oxide matrix $\left(\mathrm{AgSnO}_{2}\right)$, using stir casting and powder metallurgy processing techniques.

\section{Material selection}

The scope of electrical conductivity varies with the selection of materials based on the variations in material properties like higher conductivity, greater mechanical properties and lesser corrosion property. The best material is silver which as good conduction properties \& mechanical properties, but the material is costlier as compared with other conducting materials. The composite material based on silver is made to reduce the

\footnotetext{
* KONGU ENGINEERING COLLEGE, DEPARTMENT OF MECHATRONICS, PERUNDURAI, TAMILNADU, INDIA

** HINDUSTHAN COLLEGE OF ENGINEERING, POLLACHI MAIN ROAD, COIMBATORE - 641 032, TAMIL NADU, INDIA 
cost, by addition aluminium and other metal oxides to the silver matrix. The detail study of the property of the various material and its property is carried out, and the material composition is made for producing comparatively better material. In here Silver Aluminium tin oxide $\left(\mathrm{Ag}-\mathrm{Al}-\mathrm{SnO}_{2}\right)$ is selected for its good conduction property and mechanical property.

\section{A. Aluminum and its Alloy}

Aluminium is a concoction component in the boron bunch with image $\mathrm{Al}$ and nuclear number 13. It is a brilliant white, delicate, nonmagnetic, pliable metal. Aluminium is the third most copious component (after oxygen and silicon), and the most rich metal, in the world's outside layer There are diverse evaluations of aluminium composites utilized for different proposes. Alloying aluminium with different components enhances mechanical properties, quality fundamentally, thickness, expanding quality Some of the aluminium amalgams are arranged by there arrangement such as $1 \mathrm{xxx}$ arrangement, Aluminium 2xxx arrangement, Aluminium 3xxx arrangement, Aluminium 4xxx, Aluminium 5xxx arrangement, Aluminium 6xxx arrangement, and so on from this aluminium $6 \mathrm{xxx}$ arrangement is take for its consumption resistance and for its mechanical properties.

\section{B. Silver}

Silver is a delicate, white, brilliant move metal, it has the most noteworthy electrical conductivity of any component and the most noteworthy warm conductivity of any metal The silver is great transmitter and it additionally have a decent mechanical properties because of this it don't get fizzled simple because of sudden and regular operations amid exchanging operations Its likewise not a synthetically dynamic metal, but rather it is assaulted by nitric corrosive (shaping the nitrate) and by hot concentrated sulphuric corrosive. It has the most elevated electrical conductivity of all metals, yet its more noteworthy expense has kept it from being generally utilized for electrical purposes.

\section{Experimental work}

\section{Die perparation}

In casting, a die is a replica of the object to be cast, into which the molten material will be poured during the casting process. Die material used in this research work is mild steel. Die buckets are made to demanding guidelines of development, so they can keep going for a sensible period of time, as indicated by the quality evaluation of the example being fabricated, thus that they will rehash capably give a dimensionally adequate throwing. Model is done in AutoCAD Fig. 1 and continuous model is likewise done Fig. 2.

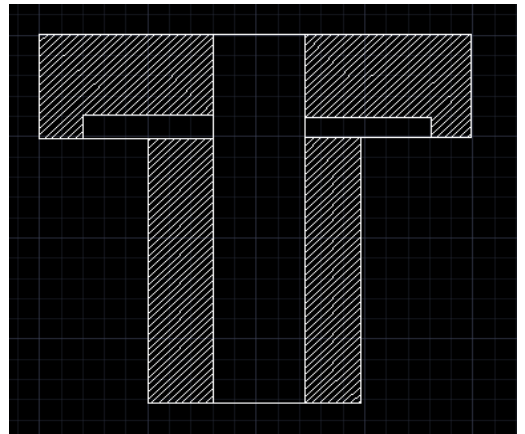

Fig. 1. AutoCAD Modelling

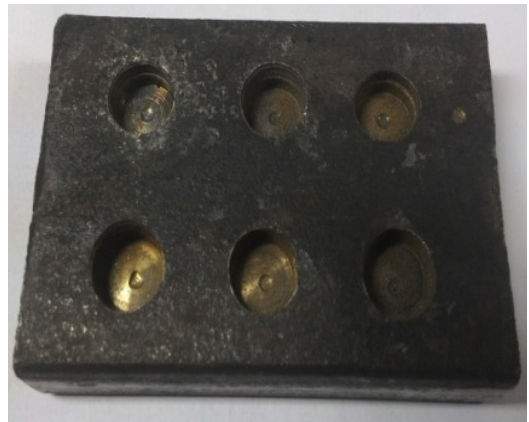

Fig. 2. Model of Die

\section{Compositions of Materials}

Composition of materials considered for the experimentation are:

Silver tin oxide

Silver tin oxide adding Indium oxide

Silver tin oxide adding tungsten oxide

Silver Aluminium

Aluminium + Silver

Silver Aluminium tin oxide

\section{E. Stir Casting}

Stir casting is a fluid state technique for composite material manufacture, in which a scattered stage (fired particles) is blended with a liquid lattice metal by method for mechanical mixing as appeared in Fig. 3. This includes fuse of earthenware particulate into fluid aluminum liquefy and permitting the blend to set are shown in Fig. 4. Here, the significant thing is to make great wetting between the particulate support and the fluid aluminum combination melt. The least complex and most monetarily utilized strategy is known as blend throwing procedure. The blend throwing strategy includes the presentation of pre-treated fired particles into the liquid amalgam made by the impeller. Small scale auxiliary can bring about outstandingly agglomeration and sedimentation in the melt and therefore amid hardening. In homogeneity of fortification dissemination in these cast segments could likewise be an issue as an aftereffect of association between suspended earthenware particles and moving strong fluid 
interface amid hardening. For the most part it is conceivable to join up to $30 \%$ fired particles in the size extent 5 to $100 \mu \mathrm{m}$ in an assortment of liquid aluminum combinations. The metal - fired molecule slurry might by exchanged specifically to a molded mold before complete cementing or it might be permitted to cement fit as a fiddle or rectangular box shape with the goal that it can be warmed to the slurry structure for further handling by procedure, for example, kick the bucket throwing and sand throw.

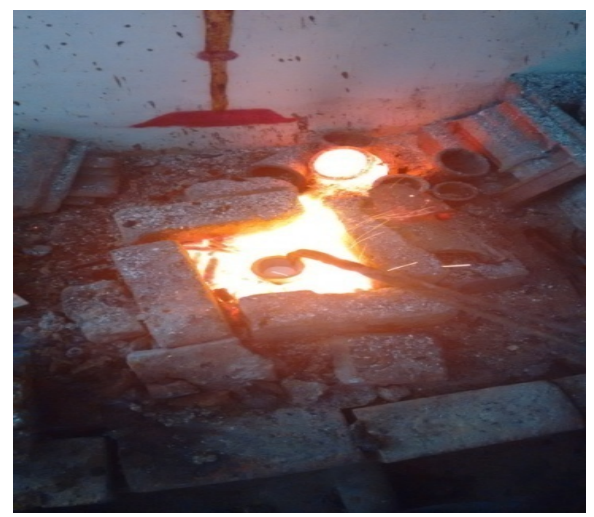

Fig. 3. Perpetration of the specimen

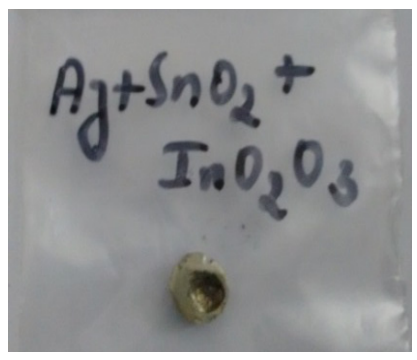

(a) Silver Tin oxide indium oxide

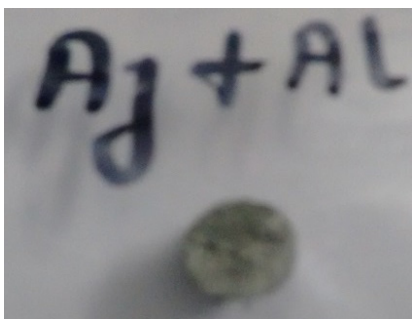

(c) Silver +Aluminum

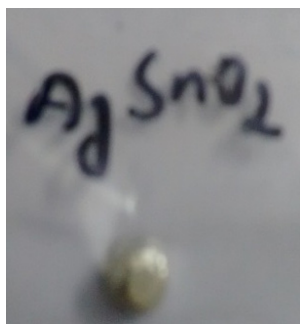

(e) Silver Tinoxide

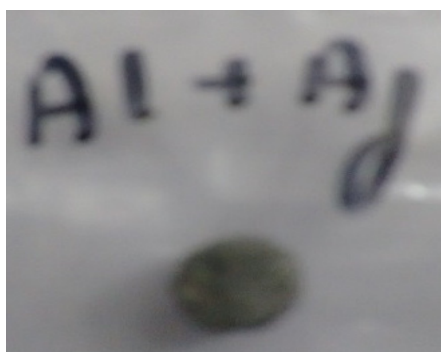

(b) Aluminum + Silver

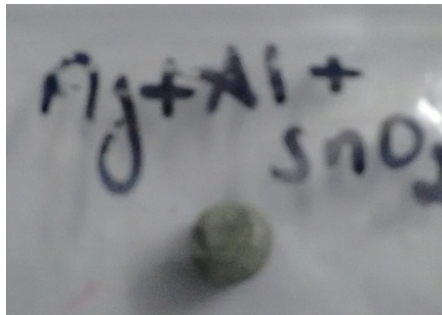

(d) Silver Aluminum Tinoxide

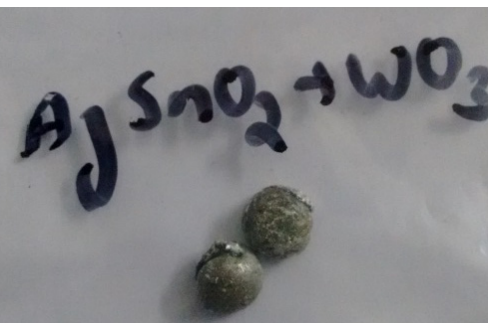

(f) Silver Tinoxide tungstenoxide
Fig. 4. Test Specimens

Our casting process starts with melting of silver in furnace. The graphite crucible with melting point of $5,530^{\circ} \mathrm{C}$ is placed in the furnace. The silver grains are placed into the crucible and taken for melting. The melting point of the silver is $961.8^{\circ} \mathrm{C}$ such that temperature is maintained at $1000^{\circ} \mathrm{C}$ throughout the process. The same procedure is followed for melting of tin oxide parallel keeping the heating temperature as $1450^{\circ} \mathrm{C}$ since melting temperature of tin oxide is $1360^{\circ} \mathrm{C}$.

\section{Powder Metallurgy}

Powder metallurgy is the procedure of mixing fine powdered materials, squeezing them into a coveted shape or frame (compacting), and after that warming the packed material in a controlled climate to bond the material (sintering). The powder metallurgy prepare for the most part comprises of four essential steps: powder make, powder mixing, compacting, and sintering. Compacting is for the most part performed at room temperature, and the lifted temperature procedure of sintering is typically directed at environmental weight. Discretionary auxiliary handling frequently takes after to acquire unique properties or upgraded accuracy. The utilization of powder metal innovation sidesteps the need to fabricate the subsequent items by metal evacuation forms, in this manner lessening costs.

Following the time when $\mathrm{Ag}-\mathrm{SnO}_{2}$ and $\mathrm{Ag}-\mathrm{ZnO}$ contact materials have risen as an ecologically cordial substitute for Ag-CdO they have been constantly enhanced with respect to their execution and appropriateness. Business generation and utilization of the $\mathrm{AgSnO}_{2}$ contact materials is constrained by their fairly poor over temperature conduct because of high contact resistance brought on by the combination of $\mathrm{SnO}_{2}$ particles in surface layers and poor workability coming about because of high hardness and bigger molecule size of $\mathrm{SnO}_{2}$ attributable to the customary assembling process [6]. These days, it is realized that the utilitarian properties of the $\mathrm{Ag}-\mathrm{SnO}_{2}$ electrical contact materials can be enhanced by expansion of a second metal oxide segment of, for example, $\mathrm{In}_{2} \mathrm{O}_{3}, \mathrm{Bi}_{2} \mathrm{O}_{3}, \mathrm{CuO}$ or $\mathrm{WO}_{3}$ which expand scattering of primary oxides $\left(\mathrm{SnO}_{2}\right)$ in silver grid and add to the actuation of sintering procedure $[7,8]$. It was found that little expansion of $\mathrm{In}_{2} \mathrm{O}_{3}$ to $\mathrm{Ag}-\mathrm{SnO}_{2}$ causes preeminent change of mechanical properties while keeping the great estimations of electrical conductivity. On the other hand, expansion of $\mathrm{WO}_{3}$ enhances sinter ability and wettability of $\mathrm{SnO}_{2}$ in liquid $\mathrm{Ag}$ in this manner enhancing the counter welding and over temperature conduct [9]. Then again, $\mathrm{Ag}-\mathrm{ZnO}$ materials use the high liquefying purpose of $\mathrm{ZnO}$ bringing about that it's breaking down is more troublesome than that of $\mathrm{SnO}_{2}$ under the same misuse conditions, in this way keeping the presence of gaps, and in addition the way that the $\mathrm{ZnO}$ particles viably secure against silver sputtering [10]. Be that as it may, aside from having low contact resistance $\mathrm{Ag}-\mathrm{ZnO}$ materials have unsuitable imperviousness to welding and more prominent propensity to contact wear [11].

\section{1) Compacting}

Powder compaction is the procedure of compacting metal powder in a bite the dust through the use of high weights. Normally the apparatuses are held in the vertical introduction with 
the punch instrument framing the base of the depression. The powder is then compacted into a shape and after that launched out from the kick the bucket hole. In some of these applications the parts might require almost no extra work for their expected use; making for extremely cost productive assembling. The thickness of the compacted powder is specifically relative to the measure of weight connected. Run of the mill weight utilized as a part of this procedure is $50 \mathrm{MPa}$ appeared in Fig. 5. Kick the bucket is produced using materials that are cleaned and wear-safe. The overwhelming innovation for the shaping of items from powder materials, as far as both tonnage amounts and quantities of parts created is die Pressing. There are mechanical, servo-electrical and water driven presses accessible in the business sector, whereby the greatest powder throughput is handled by pressure driven presses show in Fig. 6. The innovative strategy included dry and wet homogenization of powder blends, squeezing, sintering, extra mechanical treatment (fashioning) and portrayal. Than the specimens were squeezed into tablets by water driven press under the weight of $50 \mathrm{MPa}$ in a steel die

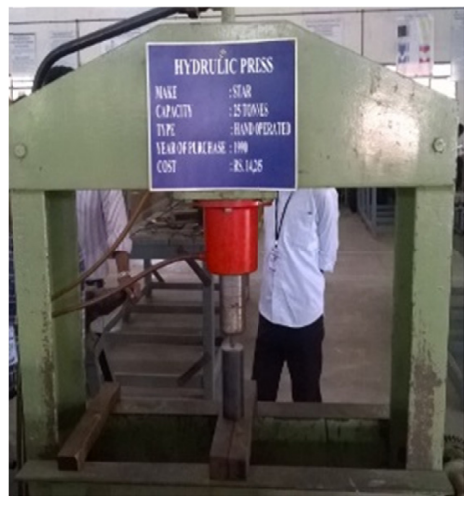

Fig. 5. Hydraulic press

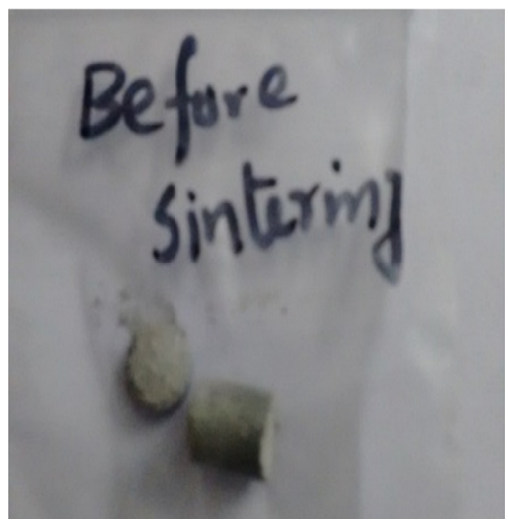

Fig. 6. Speciment before sintering

\section{2) Sintering}

Once compacted into the mold the material is put under a high warmth for a drawn out stretch of time. Under warmth, holding happens between the permeable total particles and once cooled the powder has attached to shape a strong piece. Sintering can be considered to continue in three stages. Amid the principal, neck development continues quickly yet powder particles stay discrete Fig. 9. Amid the second, most densification happens, the structure recrystallizes and particles diffuse into one another. Amid the third, disengaged pores have a tendency to end up spheroidal and densification proceeds at a much lower rate.

\section{Tests and standards}

As per the ASTM standards following are the tests carried out for the analysis of material properties.

- Conductivity test is carried out using LCR - Q meter

- Hardness is measured using the Wilson Micro Hardness Tester

- Density is calculated using the ratio of mass to volume

- Porosity is computed using Archimedes principle

- Microstructure is captured using optical microscope and

- $\quad$ Finally the X-ray Diffraction analysis is made for finding out crystalline size and chemical composition of the used composites

\section{Result and discussion}

From the experimentations the results were obtained in the following fashion and were tabulated in Table 1 for stir casting processing and Table 2 for powder metallurgy route:

\section{A. Conductivity}

Conductivity of the composite materials are calculated The resistance of the material is measured using the LCR - Q meter and the conductivity values are shown in Table 1

\section{B. Density}

Mathematically, density is defined as mass divided by volume.

\section{Porosity}

Porosity is void in the specimen which is calculated using the Archimedes Principle in this research work.

\section{Hardness}

Hardness is reliant on malleability, flexible solidness, versatility, strain, quality, strength, viscoelasticity, and thickness. The hardness is measured utilizing the miniaturized scale hardness machine. At the point when the hardware is set in holder the precious stone moulded picture is framed. Through which the hardness is measured. Hardness estimations were done in the wake of sintering and mechanical treatment on cleaned tests at room temperature utilizing a Wilson Vickers hardness analyser applying heap of $5 \mathrm{kp}$. The reported hardness qualities are a normal of three readings as appeared in Table 4. 


\section{F. Results Obtained In Stir Casting}

By the stir casting the specimens there are various results are obtained like hardness, density, conductivity, and porosity.

\section{G. Sintering Temperature}

The sintering temperature used in our research work is $800^{\circ} \mathrm{C}, 650^{\circ} \mathrm{C}$ and $450^{\circ} \mathrm{C}$. The samples were sintered for $2 \mathrm{~h}$ at $800^{\circ} \mathrm{C}$ in electro-resistive oven with programmable digital temperature controller in the air atmosphere. Subsequently the samples were annealed at $750^{\circ} \mathrm{C}$ for $30 \mathrm{~min}$ and then quenched in water.

In this varying the temperature of oven in different temperature the composite properties changes is studied in here most of the material failed at $800^{\circ} \mathrm{C}$ only $\mathrm{AgAl}-\mathrm{SnO}_{2}$ didn't get failed so it is the best material.

TABLE 1

Properties by stir casting processing

\begin{tabular}{|c|c|c|c|c|}
\hline \hline \multicolumn{5}{|c|}{ STIR CASTING } \\
\hline Specimens & $\begin{array}{c}\text { Density } \\
\text { (g/cc) }\end{array}$ & $\begin{array}{c}\text { Hardness } \\
\text { (HV5) }\end{array}$ & $\begin{array}{c}\text { Porosity } \\
\text { (\%) }\end{array}$ & $\begin{array}{c}\text { Conductivity } \\
\text { (s/m) }\end{array}$ \\
\hline $\mathrm{Ag}-\mathrm{SnO}_{2}$ & 7.704 & 70.8 & 0.4 & 19.291 \\
\hline $\mathrm{Ag}-\mathrm{SnO}_{2}-\mathrm{In}_{2} \mathrm{O}_{3}$ & 8.495 & 73 & 1.5 & 9.549 \\
\hline $\mathrm{Ag}-\mathrm{SnO}_{2}-\mathrm{WO}_{3}$ & 6.364 & 71.5 & 3.6 & 17.360 \\
\hline $\mathrm{Ag}-\mathrm{Al}-\mathrm{SnO}_{2}$ & 4.094 & 68.2 & 0.5 & 35.360 \\
\hline $\mathrm{Ag}-\mathrm{Al}$ & 2.789 & 85 & 0.8 & 23.590 \\
\hline $\mathrm{Al}-\mathrm{Ag}$ & 2.426 & 86.4 & 0.3 & 21.220 \\
\hline
\end{tabular}

TABLE 2

Properties by Powder Metallurgy processing

\begin{tabular}{|c|c|c|c|c|c|}
\hline \hline \multicolumn{7}{|c|}{ POWDER METALLURGY } \\
\hline $\begin{array}{c}\text { Tempe- } \\
\text { rature }\end{array}$ & Specimens & $\begin{array}{c}\text { Density } \\
\text { (g/cc) }\end{array}$ & $\begin{array}{c}\text { Hardness } \\
\text { (HV5) }\end{array}$ & $\begin{array}{c}\text { Porosity } \\
\text { (\%) }\end{array}$ & $\begin{array}{c}\text { Conduc- } \\
\text { tivity } \\
\text { (s/m) }\end{array}$ \\
\hline $800^{\circ} \mathrm{C}$ & $\mathrm{Ag}-\mathrm{Al}-\mathrm{SnO}_{2}$ & 7.613 & 53.75 & 0.14 & 19.0099 \\
\hline \multirow{3}{*}{$650^{\circ} \mathrm{C}$} & $\mathrm{Ag}-\mathrm{SnO}_{2}$ & 7.924 & 35 & 1.1 & 12.214 \\
\cline { 2 - 6 } & $\mathrm{Ag}-\mathrm{SnO}_{2}-\mathrm{In}_{2} \mathrm{O}_{3}$ & 7.743 & 50.6 & 1.2 & 5.997 \\
\cline { 2 - 6 } & $\mathrm{Ag}-\mathrm{SnO}_{2}-\mathrm{WO}_{3}$ & 7.286 & 71.5 & 2.3 & 6.553 \\
\hline
\end{tabular}

\section{H. Microstructure}

Microstructure is characterized as the structure of a readied surface or thin thwart of material as uncovered by a magnifying lens above $25 \times$ amplification. The microstructure of a material (which can be extensively grouped into metallic, polymeric, clay and composite) can firmly impact physical properties, for example, quality, durability, pliability, hardness, consumption resistance, high/low temperature conduct, wear resistance, et cetera, which thusly represent the utilization of these materials in modern practice from Fig. 7. More advanced microstructure examination includes higher controlled instruments: optical microscopy, electron microscopy, X-beam diffraction et cetera, some including arrangement of the material specimen (cutting, microtome, cleaning, drawing, vapour-affidavit and so forth.). The strategies are referred to all in all as metallography as connected to metals and compounds, and can be utilized as a part of altered structure for some other material, for example, earthenware production, glasses, composites, and polymers

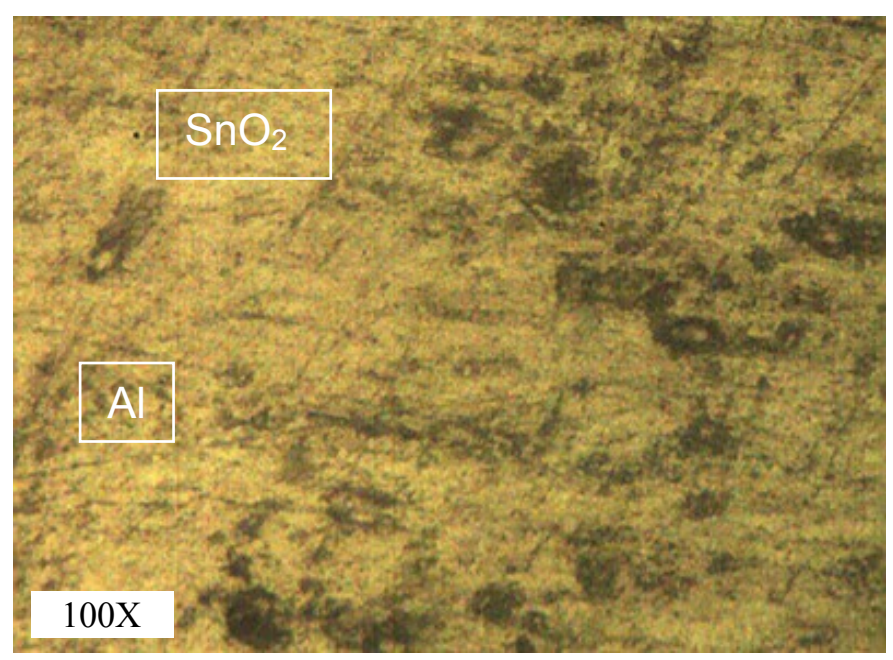

Fig. 7. $100 \times$ microstructure of powder compacted $\mathrm{Ag}-\mathrm{Al}-\mathrm{SnO}_{2}$

\section{X-Ray Diffraction}

X-ray crystallography is a device utilized for distinguishing the nuclear and sub-atomic structure of a gem, in which the crystalline particles cause a light emission X-beams to diffract into numerous particular headings. By measuring the points and intensities of these diffracted pillars, a crystallographer can create a three-dimensional photo of the thickness of electrons inside of the precious stone. From this electron thickness, the mean positions of the iotas in the precious stone can be resolved, and additionally their compound bonds, their confusion and different other data. In a solitary gem X-beam diffraction estimation, a precious stone is mounted on a goniometer. The goniometer is utilized to position the precious stone at chose introductions. The precious stone is assaulted with a finely centred monochromatic light emission beams, creating a diffraction example of consistently divided spots known as reflections. The two-dimensional pictures taken at various revolutions are changed over into a three-dimensional model of the thickness of electrons inside of the precious stone utilizing the numerical strategy for Fourier changes, joined with synthetic information known for the example. Poor determination (fluffiness) or even mistakes might come about if the precious stones are too little, or not sufficiently uniform in their inner cosmetics is shown in Fig. 8(a,b) and Fig. 9(a,b).

\section{Conclusions}

The results for stir casting and powder metallurgy process conducted in here shows that adding of Aluminum with silver and also with tin oxide gives required properties. Addition of 


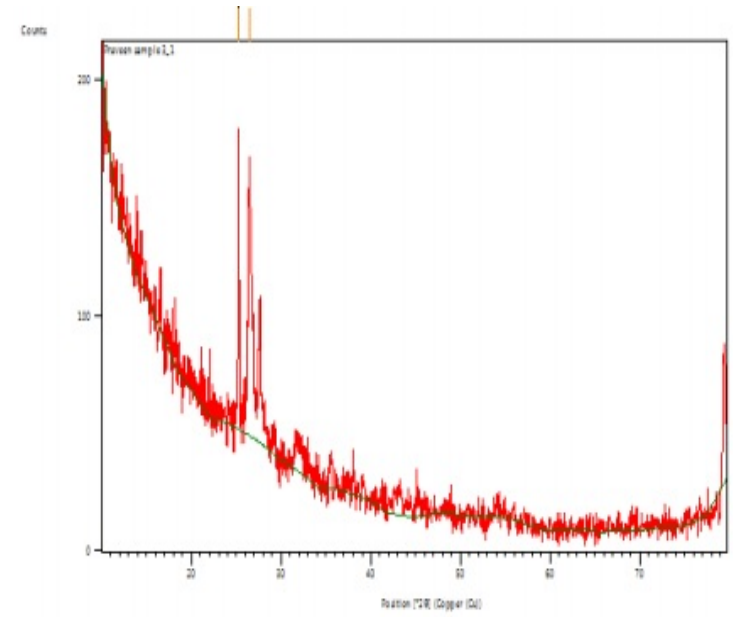

\section{Peak List}

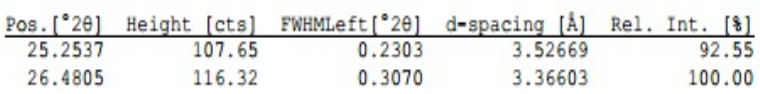

\section{Pattern List}

\begin{tabular}{|c|c|c|c|c|c|}
\hline $\begin{array}{l}\text { Visibl } \\
\text { Chem. }\end{array}$ & $\frac{\text { Ref.Code }}{\text { rmula }}$ & Score & Compound Name & Displ. $\left[{ }^{\circ} 2 \theta\right]$ & Scale Fac. \\
\hline 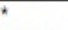 & 01-072-1147 & 17 & Tin Oxide & 0.000 & 0.587 \\
\hline $\begin{array}{ll}\text { Sn } & 02 \\
\text { Ag } & 01\end{array}$ & $98-003-5662$ & 10 & Silver(II) Oxide & 0.000 & 0.121 \\
\hline${ }^{*}$ & $01-077-8135$ & 6 & Silver Tin & 0.000 & 0.049 \\
\hline
\end{tabular}
Ag0 $0.04 \mathrm{Sn} 0.96$

Fig. 8(a). XRD for Stir casted $\mathrm{AgSnO}_{2}$

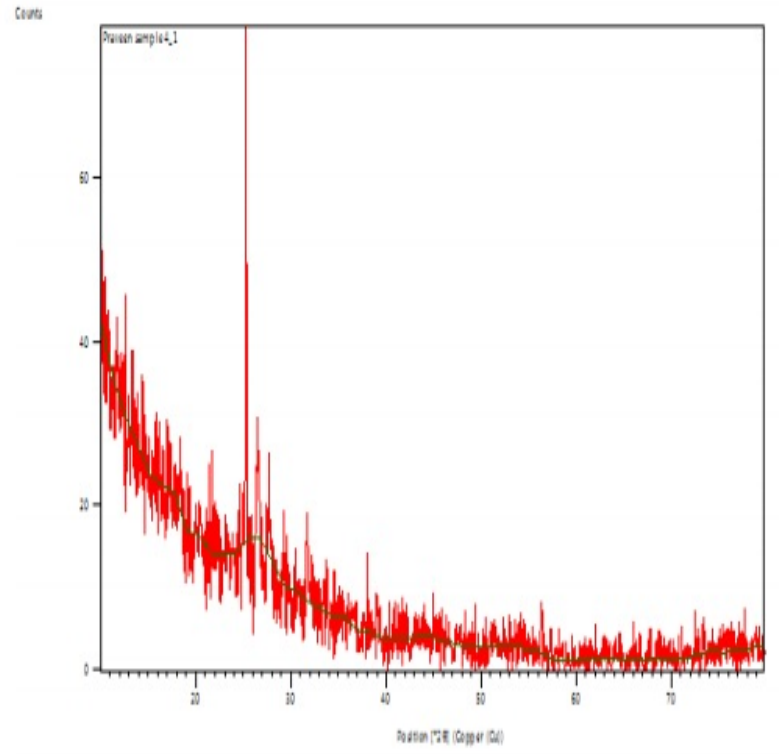

\section{Pattern List}

\begin{tabular}{|c|c|c|c|c|}
\hline \multirow{2}{*}{\multicolumn{5}{|c|}{$\begin{array}{l}\text { Visible Ref.Code } \\
\text { Chem. Formula }\end{array}$}} \\
\hline & & & & \\
\hline ॠ & $98-018-0878$ & 5 & Silver & 0.000 \\
\hline $\mathrm{Ag} 1$ & & & & \\
\hline * & $01-071-5329$ & 10 & Tin Oxide & 0.000 \\
\hline $\mathrm{Sn} 02$ & & & & \\
\hline $\begin{array}{l}\star \\
\mathrm{Ag} 0.04\end{array}$ & $\begin{array}{l}01-077-8135 \\
0.96\end{array}$ & 3 & Silver Tin & 0.000 \\
\hline
\end{tabular}

Fig. 9(a). XRD for stir casted Ag-Al-SnO

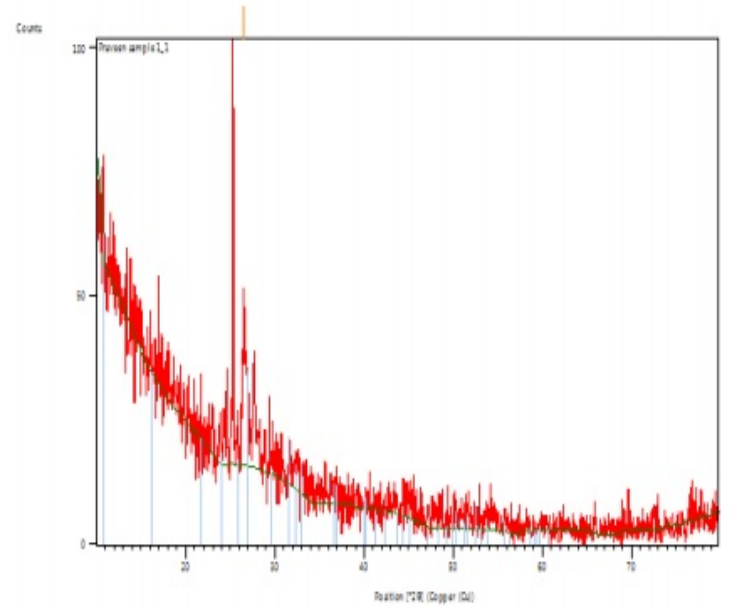

\section{Peak List}

\begin{tabular}{rrrrr} 
Pos. $\left[{ }^{\circ} 2 \theta\right]$ & Height [cts] & FWHMLeft $\left[{ }^{\circ} 2 \theta\right]$ & d-spacing [ $\AA \hat{]}]$ & Rel. Int. [8] \\
\hline 26.4718 & 14.35 & 4.4928 & 3.36432 & 100.00
\end{tabular}

\section{Pattern List}

\begin{tabular}{lrlrr} 
Visible Ref.Code & Score & Compound Name & Displ. $\left[{ }^{\circ} 2 \theta\right]$ & Scale Fac. \\
\hline Chem. Formula & & & & \\
\hline$*$ 00-021-1070 & 6 & Silver Aluminum Ox.. & 0.000 & 0.082 \\
Ag A1 02 & & & & \\
$* \quad 01-075-9497$ & 21 & Tin Oxide & 0.000 & 0.121 \\
Sn 02 & & & &
\end{tabular}

Fig. 8(b). XRD for Powder compacted $\mathrm{AgSnO}_{2}$

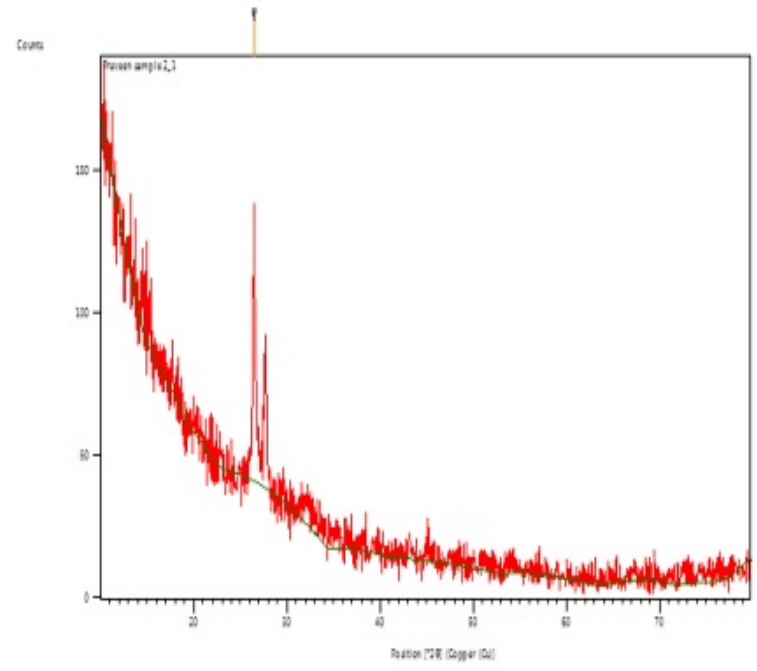

\section{Peak List}

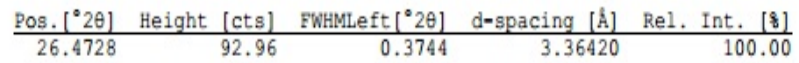

\section{Pattern List}

\begin{tabular}{|c|c|c|c|c|c|}
\hline & Formul & & & & \\
\hline $\bar{*}$ & $01-072-3440$ & 13 & Aluminum & 0.000 & 0.181 \\
\hline Al & & & & & \\
\hline$\star$ & $01-076-1489$ & 13 & Silver Oxide & 0.000 & 0.172 \\
\hline$\stackrel{A g}{A g}$ & $98-005-8353$ & 8 & Silver Tin $(0.8 / 0.2)$ & 0.000 & 0.098 \\
\hline
\end{tabular}

Fig. 9(b). XRD for powder compacted Ag-Al- $\mathrm{SnO}_{2}$ 
Aluminium in Silver matrix requires tin oxide for wetablity of composites thereby giving even more strength to the structure. The parameters influencing the processing of electrical contact materials have been identified and the experiment designs have been forecast for further processing. The parameter optimization plays a vital role for attaining the maximum properties such as conductivity, hardness, density, and porosity of composition. Silver is chosen as a matrix and the aluminum is used as reinforcement material. By this better conducting property and mechanical property of the electrical contact can be improved by this system.

\section{REFERENCES}

[1] S.K. Chung, C.R. Koch, A.F. Lynch, Flatness-based feedback control of an automotive solenoid valve, Ieee T. Contr. Syst. T. 15 (2), 394-401 (2007).

[2] J.R. Riba, A.Garcia, J.Cusidó, M.Delgado, Dynamic model for $\mathrm{AC}$ and DC contactors-Simulation and experimental validation, Simul. Model Pract. Th. 19 (9), 1918-1932 (2011).

[3] J.R.R. Ruiz, A.G. Espinosa, Design of an estimator of the kinematics of AC contactors. Int. T. Electr. Energy 19 (7), 933-948 (2009).

[4] Z. Wróblewski, A method of gamma-beta durability determination for reliability tests of brand-new AC electromagnetic contactors, Int. T. Electr. Energy 10 (4), 219-224 (2000).
[5] M. P. Paisios, C. G. Karagiannopoulos, P. D. Bourkas, Model for temperature estimation of dc-contactors with double-break main contacts, Simul. Model Pract. Th. 15 (5) 503-512 (2007).

[6] L. Jiang, Z. Li, G. Fan, L. Cao, D. Zhang, The use of flake powder metallurgy to produce carbon nanotube (CNT)/aluminum composites with a homogenous CNT distribution, Carbon 50 (5), 1993-1998 (2012).

[7] K. Liang, T.Y. Cheang, T. Wen, X. Xie, X. Zhou, Z.W. Zhao, C.C. Shen, N. Jiang, A. W.Xu, Facile preparation of porous Mn2SnO4/ $\mathrm{Sn} / \mathrm{C}$ composite cubes as high performance anode material for lithium-ion batteries. J. Phys. Chem. C 120 (7), 3669-3676 (2016).

[8] G. Wang, Y. Jianlei, J. Xueyan, Microstructure and mechanical properties of Ti-22Al-25Nb alloy fabricated by elemental powder metallurgy, Mat. Sci. Eng. A-Struct. 654, 69-76 (2016).

[9] Y. Bai, X. He, Y. Li, C. Zhu, S. Zhang, Rapid synthesis of bulk Ti $2 \mathrm{AlC}$ by self-propagating high temperature combustion synthesis with a pseudo-hot isostatic pressing process, J. Mater. Res. 24 (8), 2528-2535 (2009).

[10] C. Chen, L. Guo, J. Luo, J. Hao, Z. Guo, A.A. Volinsky, Aluminum powder size and microstructure effects on properties of boron nitride reinforced aluminum matrix composites fabricated by semi-solid powder metallurgy, Mat. Sci. Eng. A-Struct. 646, 306-314 (2015).

[11] V. Ćosović, N. Talijan, D. Živković, D. Minićand, Ž. Živković, Comparison of properties of silver-metal oxide electrical contact materials, J. Min. Metall. B 48 (1), 131-141(2012) 